\title{
Papillary neoplasms of the bronchus of low-grade malignancy
}

\author{
J . F. SM ITH A ND D. DEXTER \\ From the Department of Morbid Anatomy, University College Hospital Medical School, \\ London, W.C.1, and the Department of Pathology, St. George's \\ Hospital Medical School, London, S.W.1
}

In this paper we describe eight examples of papillary neoplasms of the bronchus in which atypical cytological features were present. In seven the lesion was localized and invasion was not present, in one extensive spread within the bronchial tree of a lobe had occurred but invasion into the lung parenchyma was doubtful. Lesions of this type receive little comment in the literature although they can be perplexing in diagnosis and management. Typical benign papillomas of the bronchus are also rare, and one is briefly described for comparison.

\section{CASE REPORTS}

CASE I This man was a physician, aged 50, a nonsmoker except for occasional cigars. Although a mild diabetic, he had been in good health until June, 1959, when a febrile illness occurred. At this time a radiograph of the chest showed a shadow in the right lower lobe which was thought to be a collapse in the posterior basal segment.

At bronchoscopy on 4 July 1959 the larynx. trachea. carina, and right main bronchus appeared normal but blood, pus, and a soft tumour were seen in the basal stem below the medial basal branch. A biopsy was taken which was not very satisfactory because of bleeding. Histological examination showed two small pieces of hyperplastic squamous epithelium with numerous vessels but no fibrous stroma and no normal bronchial wall (Fig. 1). Variation in nuclear size was considerable with occasional binucleate cells (Fig. 2) and a few mitotic figures present. A diagnosis of squamous-celled carcinoma was made and on 13 July 1959 a lobectomy was done.

In the specimen a segment of collapse and shotty induration was identified in the posterior basal area. The bronchi and all visible ramifications were slit up before fixation, and no residual tumour could be found. There was slight bronchiectasis in the posterior basal segment. Histological examination yielded no evidence of residual tumour or even of the site of removal. No squamous metaplasia was present in the bronchiectatic segment. He has remained well since.
CASE II A woman aged 55 had had bronchitis in the four winters preceding 1960 when she was admitted to the Whittington Hospital because of a further acute attack. A bronchoscopy showed some reddened mucosa in the right main bronchus. She was discharged on tetracycline therapy and had a bronchogram in November, a few weeks later. This showed a filling defect in the right main bronchus below the middle lobe orifice. On readmission to the Whittington Hospital a friable piece of tissue on the medial wall of the intermediate bronchus, just above the level of the middle lobe orifice, was seen and biopsied.

She was referred to University College Hospital for further treatment. The biopsy had been reported as squamous-celled carcinoma, but on reviewing it we were struck by the histological similarity to the biopsy of case I. Hyperplastic squamous epithelium was present with a papillary and trabecular pattern, and in some places there was an inflamed stroma of young fibrous tissue (Fig. 3). Variation in nuclear and cell size was less marked than in case I. but mitoses were more numerous (Fig. 4). Bronchial wall was not identified. A further bronchoscopy on 8 December 1960 showed a group of small white spots 1 to $2 \mathrm{~mm}$. in diameter on the medial wall of the lower lobe bronchus around which the mucosa was red. The medial basal orifice was blowing bubbles through clear mucus. There was a little projection of apparent granulation tissue at the edge of the orifice. A biopsy taken from the upper edge of the medial basal orifice showed patches of rather flat squamous epithelium lining a slightly inflamed bronchial wall.

Although invasive squamous-celled carcinoma had not been identified the atypical cytology of the first biopsy suggested that it might well be present. Thoracotomy was performed on 14 December 1960. The lower bronchus was freed and incised posteriorly. A diffuse, red, swollen area in the bronchus extended from close to the middle lobe orifice; no definite tumour was seen but, on the assumption that this might be submucous infiltration by carcinoma, it was decided to resect both middle and lower lobes.

The thickening and irregularity of the mucosa at the junction of the main bronchus to the lower and middle lobes was confirmed in the resected specimen which showed no other lesion. Histological examina- 


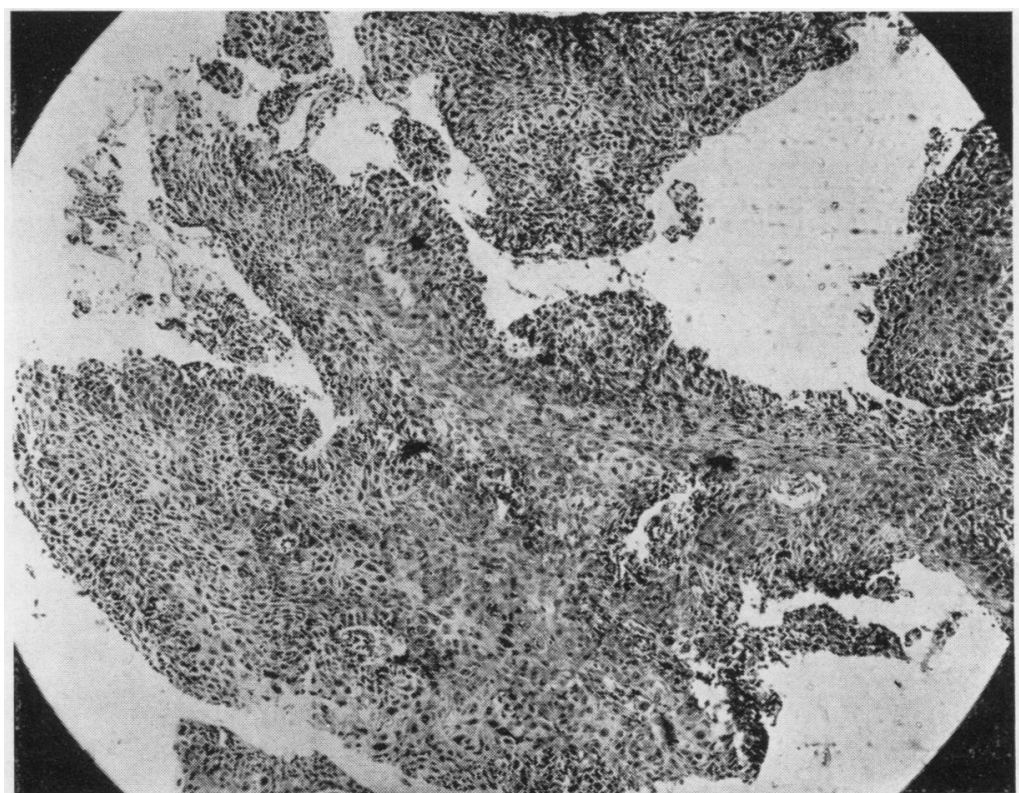

FIG. 1. Neoplastic squamous epithelium from biopsy of case I. H. and E., $\times 55$.

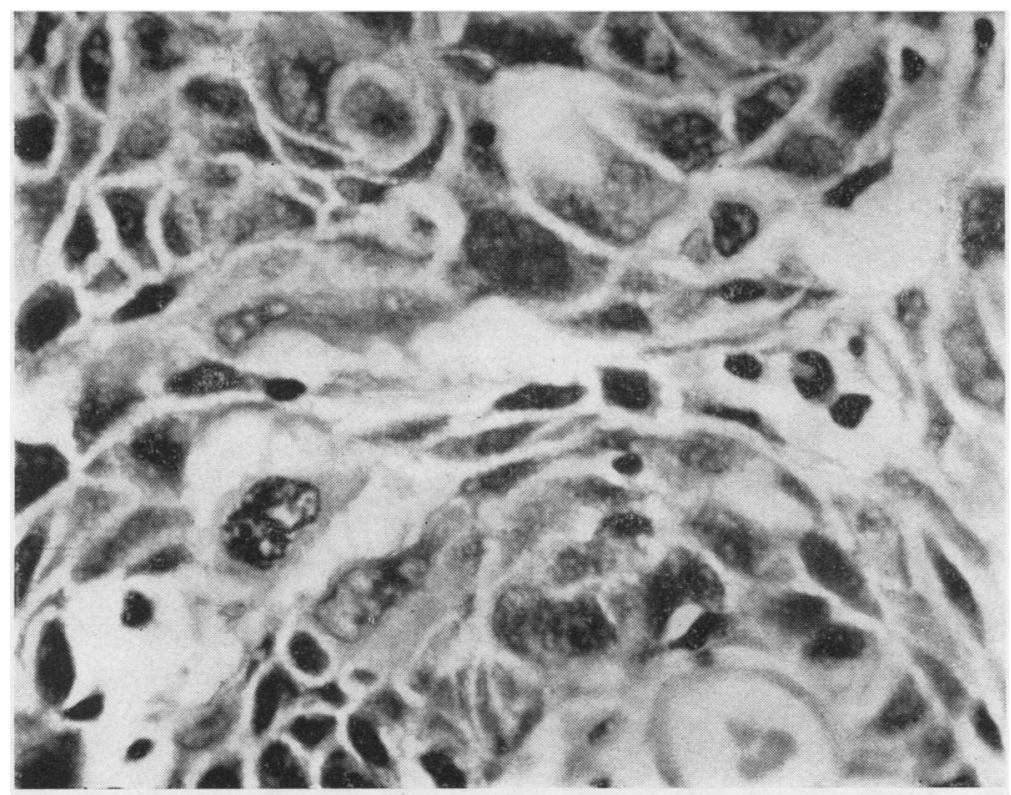

FIG. 2. High-power view of Fig. 1 showing variation in nuclear size and occasional binucleate cells. $H$. and $E, \times 670$. 


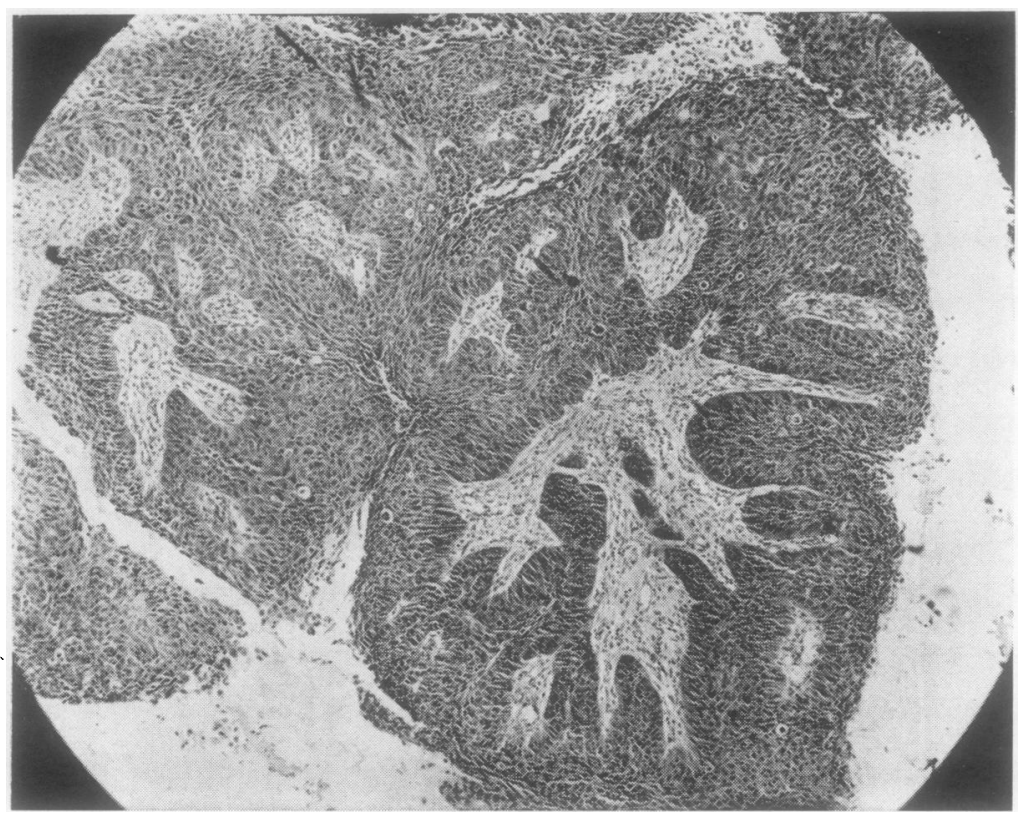

FIG. 3. Neoplastic squamous epithelium from biopsy of case II. H. and E., $\times 55$.

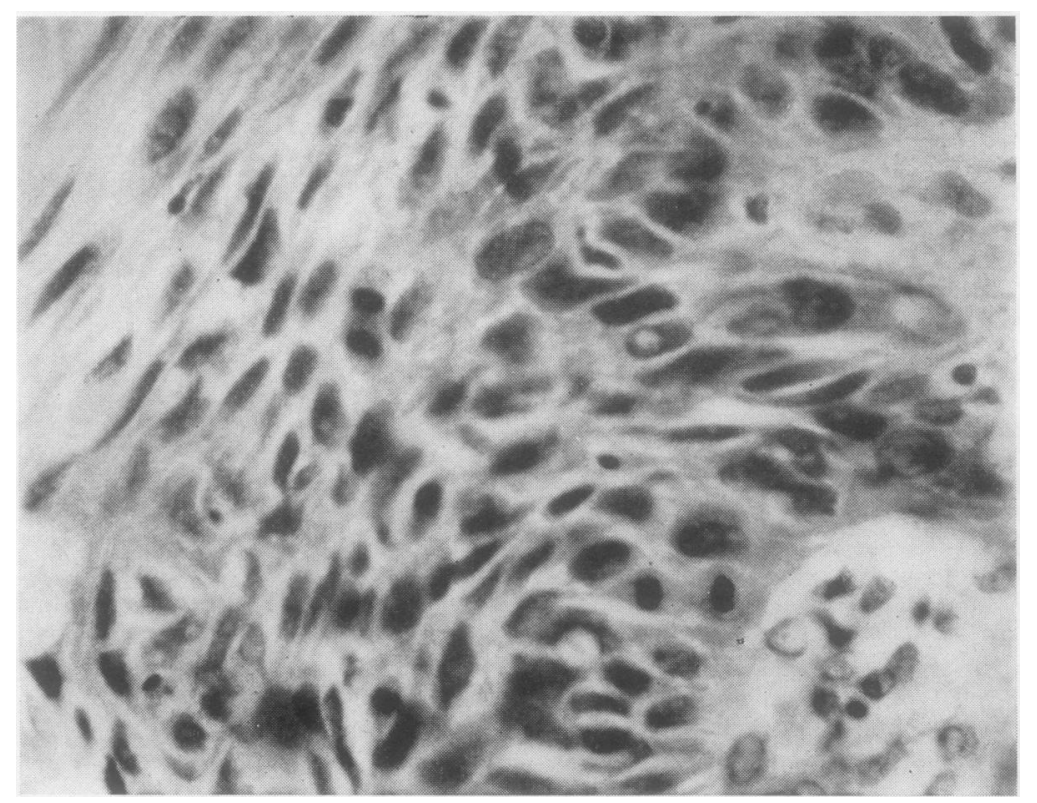

FIG. 4. High-power view of Fig. 3 showing mitoses. $H$. and E., $\times 550$. 


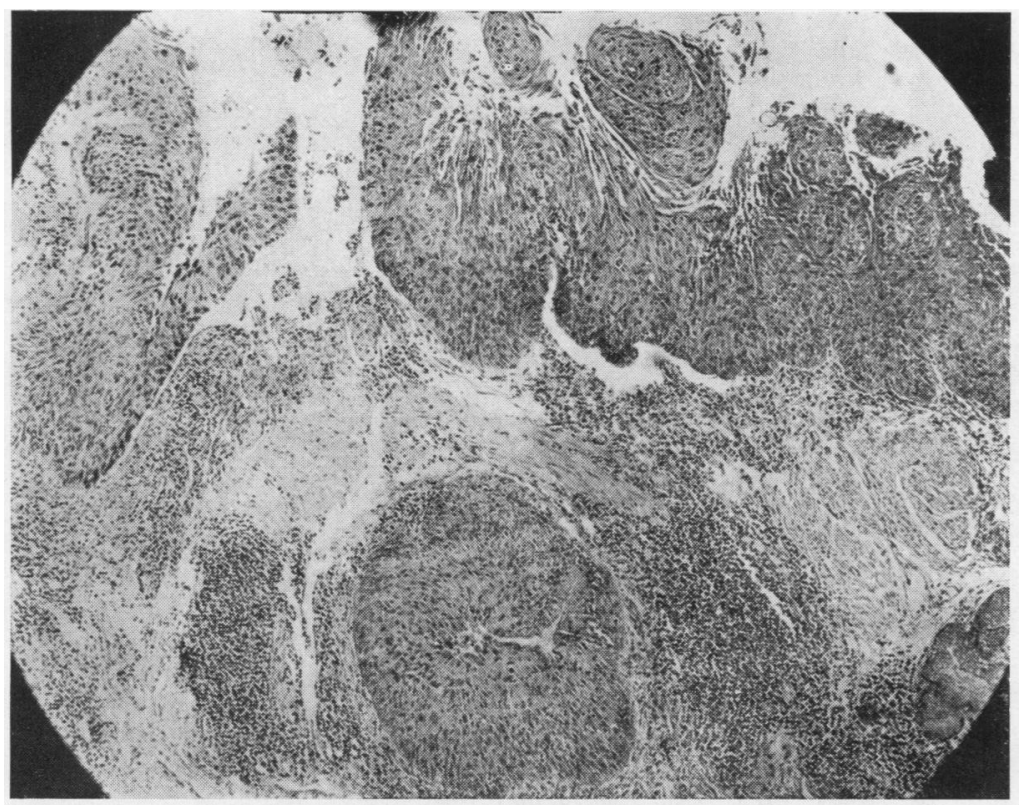

FIG. 5. Residual neoplasm at biopsy site in resected specimen from case II. Note growth extending into necks of mucous glands. $H$. and $E$., $\times 55$.

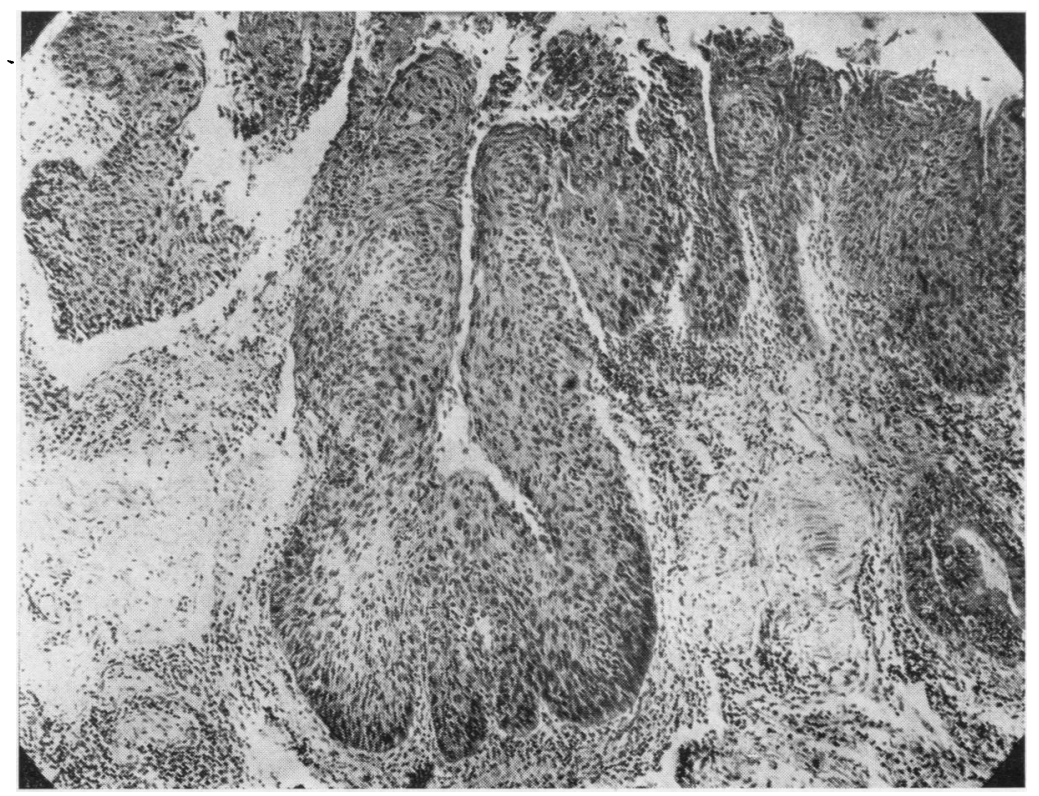

FIG. 6. Serial section from same block as Fig. 5, showing continuity of growth in neck of mucous gland and surface, i.e., there is no true invasion. H. and E., $\times 58$. 
tion of this area shows fibrin and inflammatory cells at the biopsy site and residual localized squamouscelled papillary neoplasm. The cytology is similar to that of the initial biopsy, and the growth extends into the necks of the mucous glands (Fig. 5). However, serial sections demonstrate continuity of the surface and deeper foci of the neoplasm so there is no true invasion (Fig 6). There was no evidence of squamous metaplasia in sections from other bronchi. She has remained well since.

CASE III A 61-year-old market porter had attended the London Hospital in March 1949 with a six months' history of blood-stained sputum in the early morning, following an initial small haemoptysis; a slightly larger one had made him seek medical advice. In the three months preceding the hospital visit his cigarette consumption was 10 to 20 a day ; before that it had been 40 a day. On examination he was an obese, cheerful man without physical signs. A radiograph of the chest showed some shadowing in the left mid-zone, and on examination of the sputum squamous carcinoma cells were identified on several occasions. Bronchoscopic examination was negative. At thoracotomy on 4 April 1949 there was some diffculty in locating the growth, and it was finally decided to do a left upper lobectomy. After section of the bronchus growth was seen in the lumen, so a resection of a further $\frac{1}{2}$ in. $(12 \cdot 7 \mathrm{~mm}$.) of bronchus was performed, the stump being covered with an intercostal muscle graft. The patient made an uneventful recovery and he has remained well since.

The resected specimen showed a neoplastic mass, $2.5 \times 1.5 \mathrm{~cm}$., in the main bronchus which was obstructed, the lumen being reduced to $0 \cdot 3 \mathrm{~cm}$. From it papilliferous growth extended into all the chief branches, some of which were dilated and contained thin pus in the periphery of the central part of the lung. Microscopical examination confirmed this bronchiectasis and showed the neoplasm to be a squamous papillary lesion situated at the junction of and involving the main branches to the upper lobe. In one place it appeared to be originating from a fairly wide area of bronchial epithelium; elsewhere it was extending into the lumina of bronchi. At the time this section was first examined (in 1949) it was thought that superficial invasion of the inflamed bronchial wall had occurred at one place. Re-examination now suggests that this might well be tangential section of papillary non-invasive extensions. However, there is conspicuous mitotic activity, nuclear variation, superficial keratinization, and necrosis in the growth.

Comment This was a rather extensive papillary neoplasm with cytological evidence of malignancy but no convincing invasion.

CASE IV This man, aged 66 years, was admitted to St. George's Hospital in April 1949 with a six months' history of a productive cough. the sputum being blood-stained on admission as it had been several times in the previous months. Night sweats had $\frac{C}{5}$ occurred, and he had lost two stones in weight. Details of the smoking habits were not available.

There was patchy collapse and bronchiectasis in the left lower lobe. Purulent sputum, 6 to $10 \mathrm{oz}$., was coughed up daily, and in this malignant squamous $\overrightarrow{0}$ epithelial cells were identified. Death occurred suddenly on 16 April 1949 following an attack of coughing with bronchospasm.

At necropsy a large, polypoid tumour situated at the bifurcation of the trachea was causing complete obstruction of the left and partial obstruction of the right main bronchus. Consequent to this there was bronchiectasis and collapse in the left lower lobe and patchy collapse of the right lower lobe. The tumour appeared to be confined to the lumen of the trachea, and no local or distant metastases were present. Histological examination showed a papillary squamous-celled neoplasm similar to that of case III. The epithelium of the papillae was thick with irregular and incomplete differentiation. There was considerable nuclear variation and mitotic activity and isolated trabeculae of cells within the tumour stroma. Invasion of the wall of the trachea was not present. In some areas near the tumour there was squamous metaplasia of bronchial mucosa.

CASE V A man aged 63 years, a heavy cigarette smoker for many years, developed pneumonia affecting the lingula in May 1954. He was given antibiotics $\mathbb{D}$ but resolution was slow. In the next few months he had blood-stained sputum on several occasions. In July 1954 a chest radiograph showed an area of segmental collapse. He was bronchoscoped on 10 August 1954 and a mulberry-like tumour was seen on the carina between the left upper and lower lobe bronchi. A biopsy showed a papillary tumour covered by squamous epithelium in which gross cellular irregu- $\tilde{x}_{x}$ larity with atypism was present. Numerous mitotic figures were seen. No invasion was present. A diagnosis of squamous cell carcinoma was made.

The patient had a poor respiratory reserve. It was decided to treat him by radon seed implants. At thoracotomy no tumour could be seen outside the bronchus, but the radon seeds were inserted into the $D$ peribronchial tissues. Bronchoscopy was carried out and several fragments of tumour were seen lying free $N$ in the bronchial lumen. These were removed by suc- 5 tion. After this the bronchial lumen appeared normal. $N$ It was impossible to identify the point of origin or $\underset{\mathrm{W}}{ }$ attachment of the tumour. The tumour fragments $O$ showed an identical structure with the biopsy material. Again no invasion was present. The patient attended $\stackrel{0}{\subset}$ follow-up clinics regularly and had no recurrence of $\mathbb{D}$ chest symptoms.

He was re-admitted on 2 August 1956 with acute intestinal obstruction due to a carcinoma of the sigmoid colon. Resection was carried out. A broncho- $\stackrel{\square}{\square}$ scopy was performed at the end of the operation and $\mathbb{D}$ showed no abnormality. He developed post-operative ileus and died on 15 August 1956. 
At necropsy no metastases from the bronchial carcinoma were present. A block of tissue including the carina between the left upper and lower lobe bronchi was taken and serial sections were prepared. These showed no residual neoplasm. The bronchial mucosa at the site of the tumour and from other bronchi showed a few areas of pseudostratification but no other abnormality.

CASE VI A labourer aged 60 had smoked 20 cigarettes a day for many years. He was admitted to St. George's Hospital in February 1960 with a productive cough. Radiological examination showed areas of abnormal shadow in the left upper lobe. Repeated sputum examinations for tubercle bacilli and malignant cells were negative. The patient refused to be bronchoscoped. During the next 18 months a slow increase in the size of the left upper lobe shadow occurred. On 22 August 1961 bronchoscopy showed a tumour arising from the origin of the left upper lobe bronchus. Lobectomy was carried out; it was necessary to remove part of the lower lobe bronchus. The patient appeared to be making satisfactory progress but had a massive haemorrhage and died on 21 September 1961.

The specimen consisted of the left upper lobe. There was a polypoid tumour, $1 \mathrm{~cm}$. in diameter, loosely attached to the wall of the left bronchus near its cut end. The bronchi peripheral to the tumour were dilated and filled with pus. There was patchy consolidation of the lung parenchyma.

Histologically there is a papillary tumour occupying the bronchial lumen (Fig. 7). The tumour is covered by abnormal squamous epithelium showing irregular and incomplete differentiation. Numerous mitotic figures are present (Fig. 8). There is no invasion of the stroma or of the bronchial wall. Semi-serial sections failed to reveal a point of attachment to the bronchial wall. The lymph nodes present are free from growth. There is bronchiectasis and organizing pneumonia peripheral to the tumour.

At necropsy there was no residual tumour and no metastases were present.

CASE VII A labourer, aged 48 years, who had smoked 20 to 25 cigarettes daily for many years, was admitted on 7 December 1960 complaining of a productive cough for the past five weeks. During this period he had been breathless on exertion. There was no history of haemoptysis. On examination there was partial collapse of the right upper lobe. A radiograph showed collapse of the anterior segment of the right upper lobe. A bronchogram showed complete blockage of the anterior segmental bronchus. Bronchoscopy confirmed this finding, the appearances suggesting a bronchial carcinoma. A biopsy was taken but did not include tumour tissue. Three specimens of sputum were examined but no tumour cells were seen. On 16 December 1960 a right upper lobectomy was carried out. The patient made a satisfactory post-operative recovery and remains well.

The resected specimen showed a friable papillary tumour, approximately $1 \mathrm{~cm}$. in diameter, filling the anterior segmental bronchus at its origin. The tumour was loosely attached to the bronchial wall and did not appear to be infiltrating the bronchus or the lung. The bronchi peripheral to the tumour were dilated and filled with pus. There was organizing pneumonia in the anterior segment.

Microscopical examination shows the tumour to be a papillary mass covered by abnormal squamous epithelium. There is irregular and incomplete differentiation of the epithelium and a moderate number of mitotic figures. Isolated trabeculae of tumour cells are present in its stroma. Semi-serial sections failed to reveal a point of origin from the bronchial wall. There is, however, an area of the bronchus near the tumour where the bronchial surface consists of epithelium showing similar histological features to those present in the tumour. There is no invasion of the bronchial wall. The lymph nodes are free from tumour.

CASE VIII A 52-year-old hotel valet, who smoked 10 cigarettes a day, was admitted to University College Hospital in June 1962 with a two years' history of an unproductive cough which had been worse in recent months. He had been short of breath on exertion for six months during which time swelling of the ankles and feet as well as stiffness of the wrists had also been major symptoms. For two months the left knee had been swollen and uncomfortable. On examination he was a thin man with gross clubbing of the fingers, in addition to swollen ankles and wrists and a moderate effusion into the left knee. Radiographs showed a large opacity in the apical segment of the upper lobe of the right lung and gross changes of pulmonary osteoarthropathy in the ankles and wrists. On bronchoscopy there was slight reddening of the mucosa of the right upper lobe bronchus but the apical segment branch was not seen. The sputum contained cells highly suggestive of squamous-celled carcinoma. A right upper lobectomy was performed and after an initial post-operative infection he made a satisfactory recovery. The joints were more comfortable the day after operation, and five days later pain had disappeared.

The resected specimen consisted of the right upper lobe together with the lateral segment of the middle lobe. On opening the bronchi a white cauliflower-like mass, about $5 \mathrm{~cm}$. in diameter, was seen arising from the apical segment bronchus and filling a dilated part of it (Fig. 9). Distal to this growth there was some dilatation of bronchi and immediately beneath the pleura an indurated area of chronic pneumonia. No growth was seen in seven hilar glands or in a gland sent as a separate specimen.

On microscopical examination the tumour was a papillary squamous-celled neoplasm arising from the wall of the bronchus, extending along its lumen and that of some of its branches. A few islands of growth were isolated in the fibrous stroma, but convincing invasion of the adjacent parenchyma was not seen. There was conspicuous nuclear variation, mitotic 


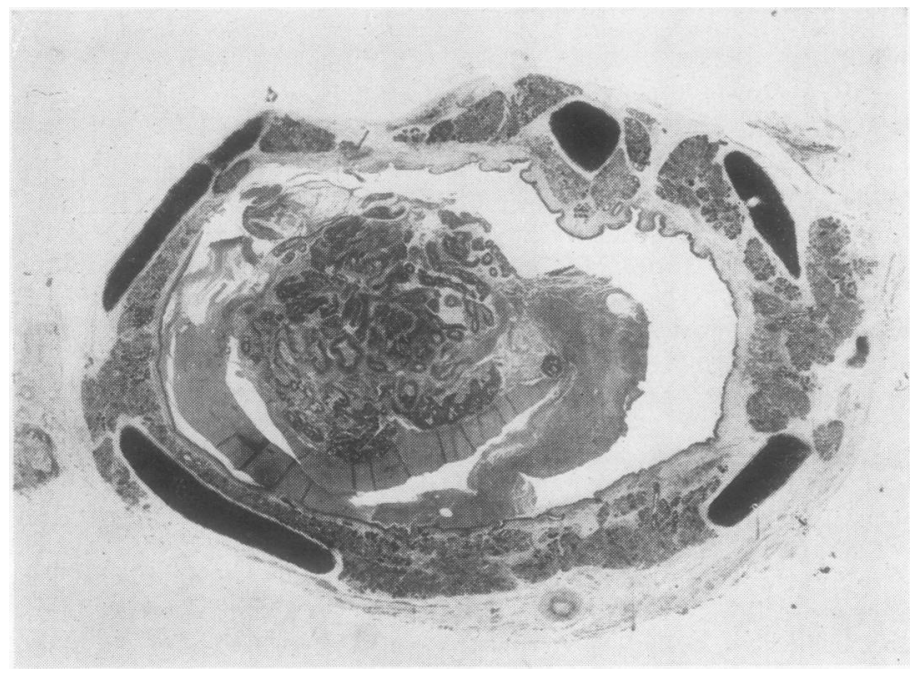

FIG. 8. High-power view of tumour in Fig. 7 showing mitotic activity. $H$. and $E$. $\times 700$.

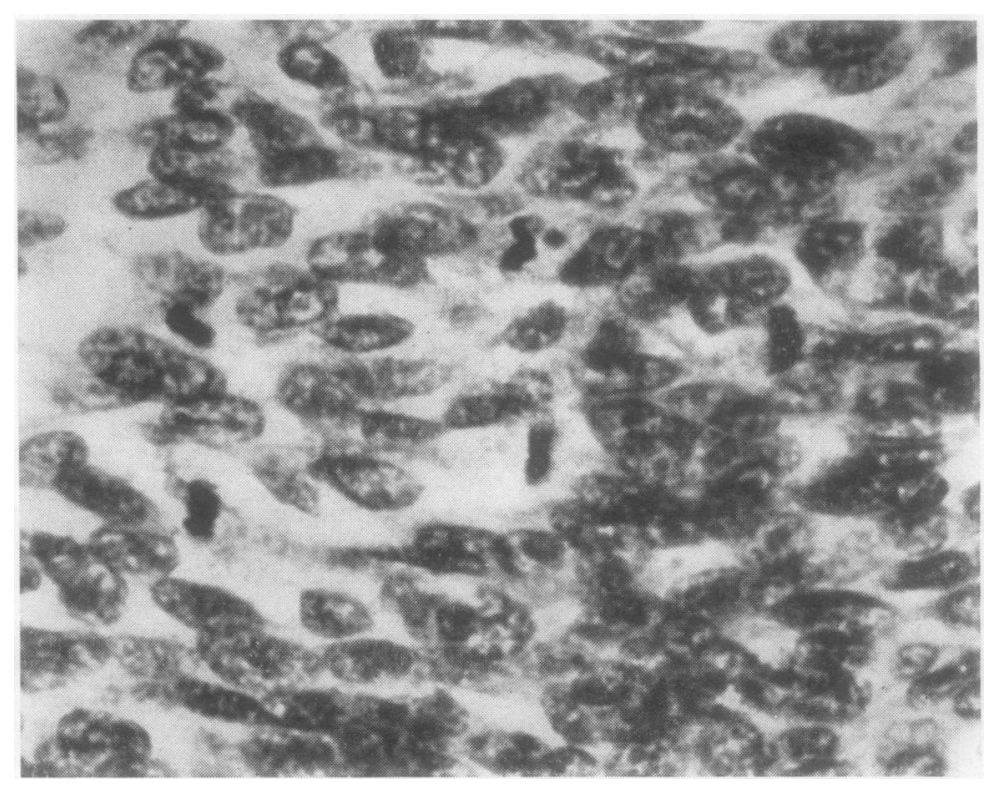
lumen of bronchus. $H$. and $E$., $\times 5$.

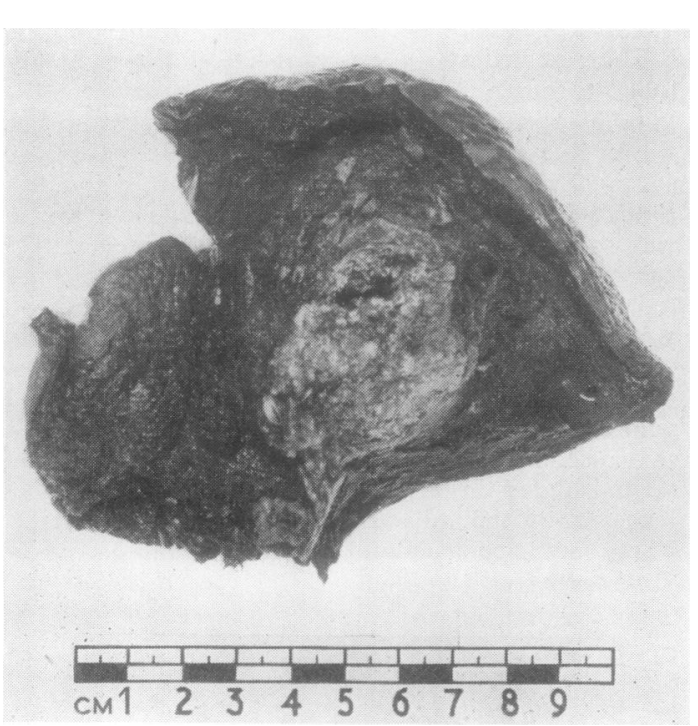

FIG. 9. Cut surface of resected upper lobe from case VIII showing cauliflower-like mass filling a dilated apical segment bronchus. 


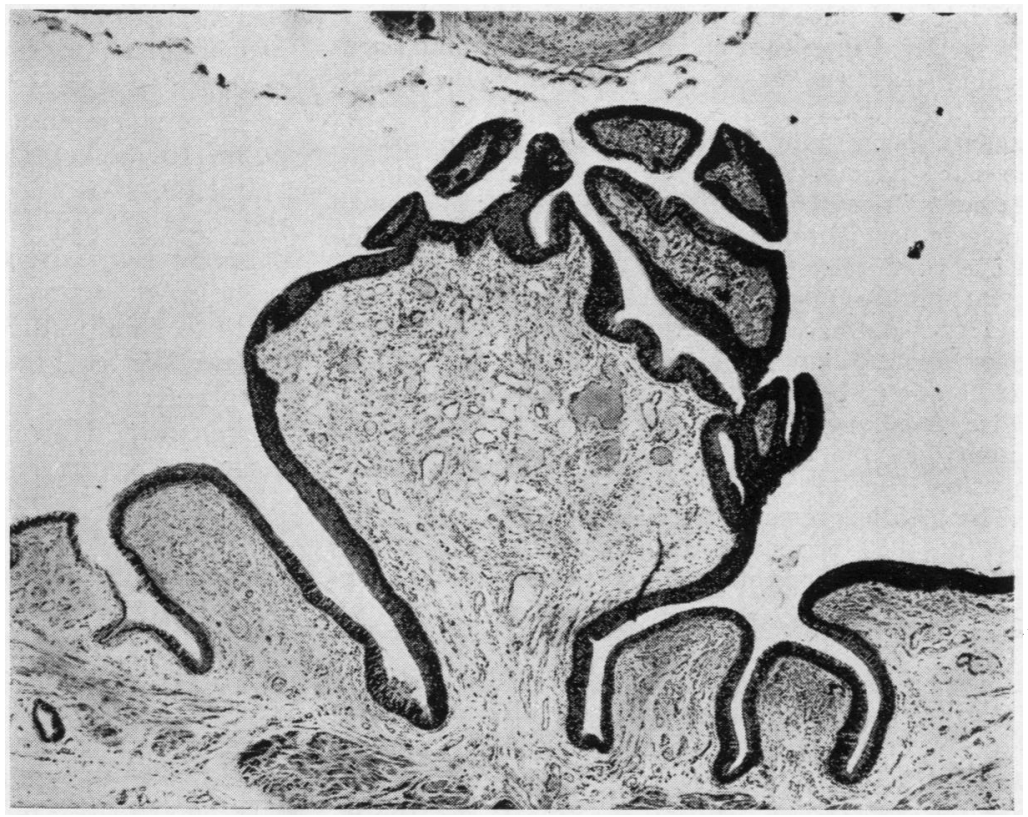

FIG. 10. Squumous-celled papilloma resected from case IX. Note vascular fibrous core. $H$. and $E$. $\times 30$.

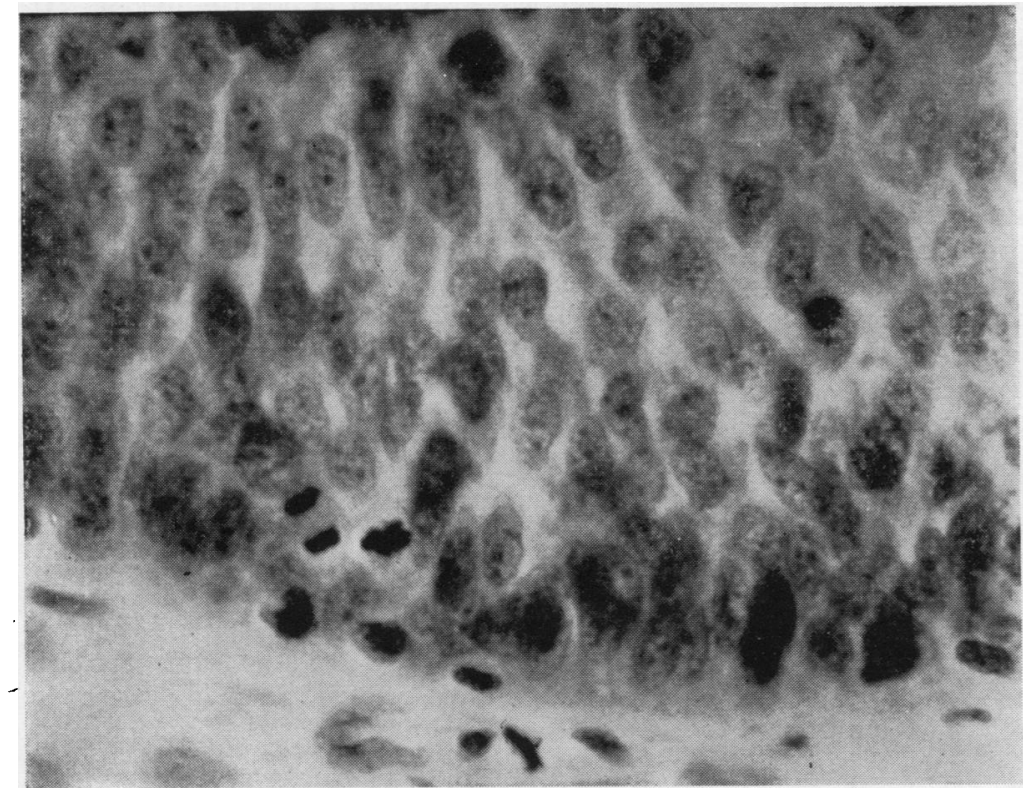

FIG.11. High-power view of basal layer of epithelium of papilloma in Fig. 10. Crowding of nuclei and mitotic activity. H. and E., $\times 800$. 
activity, and incomplete maturation of epithelium. The adjacent lung showed collapse and chronic pneumonia. There was no secondary growth in the glands.

CASE IX This middle-aged man was a non-smoker. He had a haemoptysis in 1958 and was referred to Sir Clement Price Thomas. On bronchoscopy a small polyp in the right upper lobe bronchus was seen and a sleeve containing this growth was resected at subsequent thoracotomy. The resected bronchus was about $3 \times 1 \mathrm{~cm}$. and showed at its centre a small papillary lesion about $3 \mathrm{~mm}$. in diameter (Fig. 10). Microscopic examination showed this to be a small squamouscelled papilloma with nuclear crowding and mitotic activity in the basal layer but no suggestion of invasion (Fig. 11).

The man has remained well except that in the latter part of 1960 he had streaking of the sputum. His radiograph remained normal and he refused bronchoscopy.

\section{DISCUSSION}

Pathologists differ in their interpretation of the distinction between benign and malignant tumours. Willis (1960) stresses that the terms are relative, that the distinction between the two is not fundamental or clear-cut, and that the intelligent question to ask is, 'How innocent or malignant is this tumour?' On the other hand, Payling Wright (1958) stresses the distinction with the forthright phrase, 'To confuse these two valuable antonyms is pure transcendentalism and does disservice to clear thought on a difficult problem'. Until recently this question has not excited much interest in connexion with squamous epithelial neoplasms of the bronchus. Willis (1960) and Liebow (1952) mention the occurrence of papillomas but give few descriptive details. Liebow (1952) illustrates an example of widespread extension of papillomatosis of the larynx to the trachea and bronchi. We have examined specimens from a somewhat similar case in which so far the extension has reached the lower trachea. In the numerous biopsy specimens there is no evidence of atypical features except for an occasional mitosis. We think the histology of case IX is similar and that it should be regarded as a papilloma. This is the only solitary papilloma in the bronchial tree that we have encountered; the history of further slight haemoptysis in this case is disquieting. It is possible that case IX represents the earliest stage of the neoplasms seen in cases I to VIII, and that its natural evolution would be to such a lesion.

We consider that cases I to VIII are examples of low-grade papillary carcinomas. In none of them is there convincing evidence of invasion. All protruded into the bronchial lumen and in one, case
III, extensive spread along the lumina of the bronchi of an upper lobe had occurred. All showed evidence of nuclear variation and mitotic activity. In those where enough tissue was available for the point to be assessed, the maturation of the epithelium was variable or incomplete. These are the cytological features of intra-epithelial carcinoma or carcinoma in situ. However, those pathologists who use these terms appear to be loath to employ them in connexion with papillary lesions. We have therefore used the term "papillary $\overrightarrow{\vec{\infty}}$ neoplasms of the bronchus of low-grade malignancy'. Hinson (1958) makes the point that a carcinoma may initially be polypoid within the lumen of the bronchus, but he does not discuss the presence or absence of local microscopical invasion in such neoplasms.

It is probable that the presence or absence of $\overparen{\varnothing}$ such invasion can only be determined in the re- $\frac{3}{8}$ sected lobe or at necropsy. It may be possible, 只 however, to recognize that the lesion is one of this type if the bronchoscopic and histological findings are considered together. Thus in case $\mathbf{V}$ the tumour was described as mulberry-like on bronchoscopic examination, and in case VIII as cauliflower-like in the resected lobe (this tumour was not accessible to the bronchoscope). In the latter example the tumour tissue was friable, easily coming away in pieces. Cases I and II were so friable that most or all of the tumour came away with the biopsy; the word friable was also used in describing case VII.

If a friable polypoid tumour on bronchoscopy shows a histological and cytological picture comparable with that illustrated in Figs. 1 to 6 , it would be worth considering if it belongs to the group delineated here. A similar group has been described recently by Sherwin, Laforet, and Strieder (1962) under the name 'exophytic endobronchial carcinoma'. They give an account of nine lung carcinomas that were characterized by a 웅 predominantly endobronchial growth of a papillo- $D$ matous, polypoid, or verrucous nature. (One of us, 을 J. F. S., had given a preliminary account of three N of the cases reported in this paper to the Pathological Society of Great Britain and Ireland in 1961 under the title Warts of the Bronchus.) However, of the nine cases described by these authors, several had microscopical evidence of invasion 0 of the bronchial wall although none had metasta- $\overparen{\Phi}$ sized. In our group we found no such invasion, $\stackrel{\mathscr{P}}{?}$ although it was only excluded in several cases by careful semi-serial sections.

It is not within our province to discuss the clinical management of these cases, but it is worth while to consider briefly the responsibility of the 
pathologist confronted with such tissue as that provided by cases I to VIII when reporting on bronchial biopsies. Before encountering these it had been our policy to regard hyperplastic squamous epithelium from this site, in which atypical cytological features were present, as indicative of carcinoma, whether or not invasion was demonstrated. Investigations of carcinoma in situ reported by Auerbach, Gere, Forman, Petrick, Smolin, Muehsam, Kassouny, and Stout (1957) and by Valentine (1957) had indicated its association with invasive carcinoma. Black and Ackerman (1952), in discussing the problem, stated that if such a lesion were found in biopsy material it could be assumed that invasive carcinoma was present also. This is no longer so. One should comment in a report on the presence or absence of invasion in the tissue available for examination. Woolner, Andersen, and Bernatz (1960) have recently reported a series of 15 cases of in situ or early invasive carcinoma. While the histological appearances of their cases were similar to those in the present series, the tumours they report were situated in the bronchial wall and none showed the well-defined papillary structure occupying the bronchial lumen.

We do not propose to discuss the clinical features of the group. So far as it can be ascertained the prognosis is good, reflecting the absence of invasion rather than the atypical cytology. Seven of our group of eight were in men. The incidence is as yet difficult to determine. The four cases from St. George's Hospital occurred in a 12year period in which 660 specimens of bronchial carcinoma were encountered as surgical or postmortem specimens. The three cases from University College Hospital were seen over a three-year period in which 54 resections of lung for carcinoma were possible. The nine cases of Sherwin et al. were encountered in a study of 85 patients with lung cancer suitable for definitive resection by one thoracic group at one hospital over a 16-year period.

\section{SUMMARY}

The pathological features of a group of low-grade squamous-celled carcinomas of the bronchus are outlined; one papilloma is included for comparison.

The essential features are a warty or mulberrylike projection into the lumen of the bronchus and an absence of invasion into the bronchial wall on histological examination. Atypical cytological features similar to those of typical invasive carcinoma may be present, but a papillary architecture is constant. Extensive spread within the lumen of the bronchus sometimes occurs.

We thank the following clinicians for permission to use their case notes: Dr. Howard Nicholson, Professor R. S. Pilcher, Sir Clement Price Thomas, Mr. .V. C. Thompson, Mr. A. H. M. Siddons, and Miss Doreen Nightingale.

Dr. Sybil Robinson kindly provided the initial biopsy sections from case II. We thank Mr. A. Bligh for the photomicrographs.

\section{REFERENCES}

Auerbach, O., Gere, J. B., Forman, J. B., Petrick, T. G., Smolin, H. J., Muehsam, G. E., Kassouny, D. Y., and Stout, A. P. (1957). Changes in the bronchial epithelium in relation to smoking and cancer of the lung; a report of progress. New Engl. J. Med., 256, 97.

Black, H. and Ackerman, L. V. (1952). The importance of epidermoid carcinoma in situ in the histogenesis of carcinoma of the lung. Ann. Surg., 186, 44.

Hinson, K. F. (1958). In Carcinoma of the Lung. Ed. J. R. Bignall. Livingstone, Edinburgh and London.

Liebow, A. A. (1952). Atlas of Tumor Pathology, Sect. V, Fasc. 17 Tumours of the lower respiratory tract. Armed Forces Institute of Pathology, Washington.

Sherwin, R. P., Laforet, E. G. and Strieder J. W. (1962). Exophytic endobronchial carcinoma. J. thorac. cardiovasc. Surg., 43, 716,

Valentine, E. H. (1957). Squamous metaplasia of the bronchus; a study of metaplastic changes occurring in the epithelium of the major bronchi in cancerous and noncancerous cases. Cancer, 10, 272.

Willis, R. A. (1960). Pathology of Tumours, 3rd ed. Butterworth London.

Woolner, L. B., Andersen, H. A., and Bernatz, P. E. (1960). "Occult" carcinoma of the bronchus : A study of 15 cases of in situ or early invasive bronchogenic carcinoma. Dis. Chest, 37, 278.

Wright, G. Payling (1958). An Introduction to Pathology, 3rd ed. Longmans Green, London. 